\title{
Study on functional outcome of bimalleolar ankle fractures treated by open reduction and internal fixation
}

\author{
Nithin Gangadhran ${ }^{1 *}$, Manju G. Pillai² \\ ${ }^{1}$ Department Of Orthopaedics, KMCT Medical College, Calicut, Kerala, India \\ ${ }^{2}$ Department Of Orthopaedics, Pushpagiri Insititue of Medical Sciences, Thiruvalla, Kerala, India
}

Received: 30 December 2020

Revised: 01 April 2021

Accepted: 02 April 2021

\section{*Correspondence:}

Dr. Nithin Gangadhran,

E-mail: drnithinortho86@gmail.com

Copyright: (c) the author(s), publisher and licensee Medip Academy. This is an open-access article distributed under the terms of the Creative Commons Attribution Non-Commercial License, which permits unrestricted non-commercial use, distribution, and reproduction in any medium, provided the original work is properly cited.

\begin{abstract}
Background: Ankle injury is the most common weight bearing orthopaedic musculoskeletal trauma encountered in emergency medicine and practice. Ankle joint is highly congruous and any disturbance of normal articular relationship may result in some progressive arthrosis of biomechanical dysfunction. As with all intra-articular fractures it necessitates accurate reduction and stable internal fixation. The objectives were to study the functional outcome of surgical treatment of bimalleolar ankle fractures and to know the complications of open reduction internal fixation of bimalleolar fractures.

Methods: 45 patients with malleolar fractures were included in this prospective longitudinal interventional study. Patients who underwent operative treatment were followed up regularly for 6 months with OPD visits and X-ray imaging at each stage. Patient parameters were recorded at immediate post op period, 6 weeks, 12 weeks and 24 weeks. Baird and Jackson scoring system for ankle were used for the functional outcome measurement.

Results: Most common type of injury pattern was supination-external rotation with 21 cases (47\% of cases). The results are excellent to good in $65 \%$ of patients, $27 \%$ of patients had fair and $8 \%$ had poor result. Syndesmotic screw fixation was done with $4.5 \mathrm{~mm}$ cortical screw in 7 cases. Most common complication was surgical site infection in 3 cases $(6.67 \%) .2$ patients underwent implant removal due to unresolved infection at 3 months.

Conclusions: The results of operative fixation were satisfactory in $90 \%$ of patients. Most of the complications were minor and resolved within three weeks.
\end{abstract}

Keywords: Bimalleolar fracture, Baird and Jackson scoring, Functional outcome of ankle fracture, Operative management

\section{INTRODUCTION}

Ankle injury is the most common weight bearing orthopaedic musculoskeletal trauma encountered in emergency medicine and practice. ${ }^{1}$ There is an increase in incidence of ankle fractures in the older patients population due to increased propensity to falls, increased weight and polypharmacy.
Ankle joint is highly congruous and any disturbance of the normal articular relationship may result in some progressive arthrosis in some biomechanical dysfunction. ${ }^{1}$ In the clinical setting determination of ankle stability is critical when planning fracture management. Stable fracture can be treated conservatively with good results although outcomes in the management of unstable ankle fractures are often better with surgical treatment. The superiority of open reduction internal fixation over closed 
treatment have been thoroughly demonstrated in the literature. $^{2}$

Malleolar fractures are one of the most common fractures in orthopaedic traumatology. As with all intra articular fractures, malleolar fractures necessitate accurate reduction and stable internal fixation. Lateral malleolar fractures in the setting of a competent deep deltoid ligament can usually be treated non-operative with good results. In contrast, a lateral malleolar fracture with an incompetent deep deltoid ligament is clinically equivalent to a bimalleolar ankle fracture and may result in talar subluxation and degenerative arthritis when treated nonoperative. ${ }^{3}$ The objective of this study was to study the functional outcome of surgical treatment of bimalleolar ankle fractures and to know the complications of open reduction internal fixation of bimalleolar fractures.

\section{METHODS}

Prospective interventional study was done on patients with bimalleolar fractures of ankle who attended Pushpagiri institute of medical science and research centre, Thiruvalla, Kerala between December 2012 and November 2014. Study was conducted after obtaining prior approval from ethics committee of the institution. A written informed consent was taken from all patients after explaining the detailed nature of the study. During the study all consecutive subjects with bimalleolar fractures of ankle in age group of 20 to 70 years were selected and operated upon by same team of orthopaedic surgeons and followed up for a period of 6 months.

\section{Exclusion criteria}

Patients below 20 and above 70 years of age, with medical contraindications to surgery, with paralytic limb, open fractures and other associated fractures in the same limb were excluded from the study.

A population of 100 was taken and a confidence level of $95 \%$ was set. Confidence interval of 15 was selected based on worst case percentage as $50 \%$ and required sample size was calculated as 30 . Several previous studies were based on similar sample size. A total of 63 patients had attended the casualty with bimalleolar fractures of ankle and out of these 8 patients had open fractures, 6 patients were above the age of 70 years and 4 had other fractures in same limb. Hence 45 patients who satisfied the inclusion criteria were selected for the study. Patients who underwent operative treatment were followed up regularly for 6 months with OPD visits and X-ray imaging at each stage. Patient parameters were recorded at immediate post-op period, 6 weeks, 12 weeks and 24 weeks. Baird and Jackson scoring system for ankle were used for the functional outcome measurement. Ankle ranges of movements were measured with goniometer. Baird and Jackson score for each patient was critically analyzed and outcome of each patient categorised as excellent, good, fair and poor depending on total scores. Data was entered into Microsoft excel and analyzed using SPSS software. Association between various factors were assessed using chi square test and $p$ value $<0.05$ was set as statistically significant.

\section{RESULTS}

Forty five cases of bimalleolar fractures managed surgically by various techniques are presented. The study comprises of $56 \%$ female patients and $44 \%$ male patients. Most common age group affected is 61-70 years (32\%, 14 cases). Right side was involved in 26 cases $(58 \%)$ compared to left side (19 cases). Twisting injury following domestic fall was major cause of injury constituting $71 \%$ of the patients. Supination-external rotation injury type was the most common fracture pattern constituting $47 \%$ of the cases. Surgical techniques used were open reduction and internal fixation of lateral malleolus with 1/3rd tubular plate/recon plate with or without syndesmotic screw fixation and the medial malleolus with $4 \mathrm{~mm}$ cannulated cancellous/malleolar screws or tension band wiring. Most common complication faced was postoperative skin infection in 3 cases and 2 patients among them had to undergo implant removal at 3 months. Chances of nonunion of medial malleolus due to periosteal interposition is avoided by open reduction. Understanding the mechanism of injury is essential for good reduction and internal fixation. The bend of lateral malleolar should be reproduced during lateral plating for fibula. Fibular length should be maintained for good ankle stability. Good anatomical reduction is essential for good clinical outcome irrespective of the type of fracture. At the end of the study excellent to good results were seen in $29(65 \%)$ cases, 12 $(27 \%)$ cases had fair results and $4(8 \%)$ had poor result. Statistical analysis was done and found that age of the patient was a significant determinant of postoperative functional outcome and pain. ( $\mathrm{p}$ value 0.002 and 0.011 respectively).There was no statistical significance of postoperative outcome with respect to sex of the patient, mode of injury, type of injury, co-morbidities.

\section{Age distribution}

14 patients (32\%) were from 61-70 year age group followed by $13(29 \%)$ patients each in 51-60 and 41- 50 years age group (Figure 1). The youngest patient was 23 year old and oldest was 70 year age. The mean age in this study is 53.5 years.

Statistical analysis of data was done for age and complications and chi-square value was found to be 8.753 and $\mathrm{p}$ value was calculated to be 0.460 . There was no statistical significance noted in the study.

Statistical analysis of age and pain was done and chisquare value was 9.033 and $\mathrm{p}$ value 0.011 , which was found to be significant.

Statistical analysis of age and result was done and chisquare value was 14.562 and $\mathrm{p}$ value 0.002 which was found to be significant. 
Younger patients had better tolerance level to pain and hence their functional outcome was better with respect to older patients in this study.

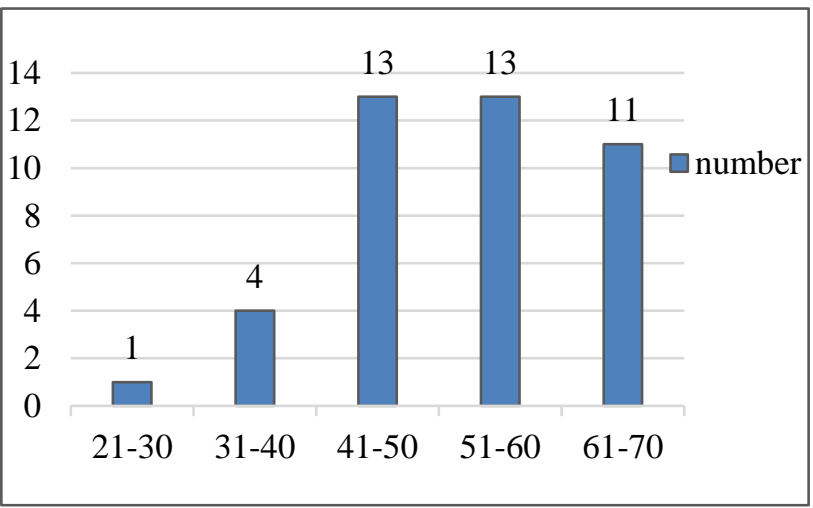

Figure 1: Age distribution.

\section{Sex distribution}

Majority of the patients were females $25(56 \%)$ patients and $20(44 \%)$ patients were males (Figure 2).

Analysis of sex and result was done and chi-square value was 1.286 and $\mathrm{p}$ value was 0.526 which was found to be statistically insignificant.

Analysis of sex and result was done and chi-square value was 2.131 and $p$ value was 0.546 which was found to be statistically insignificant.

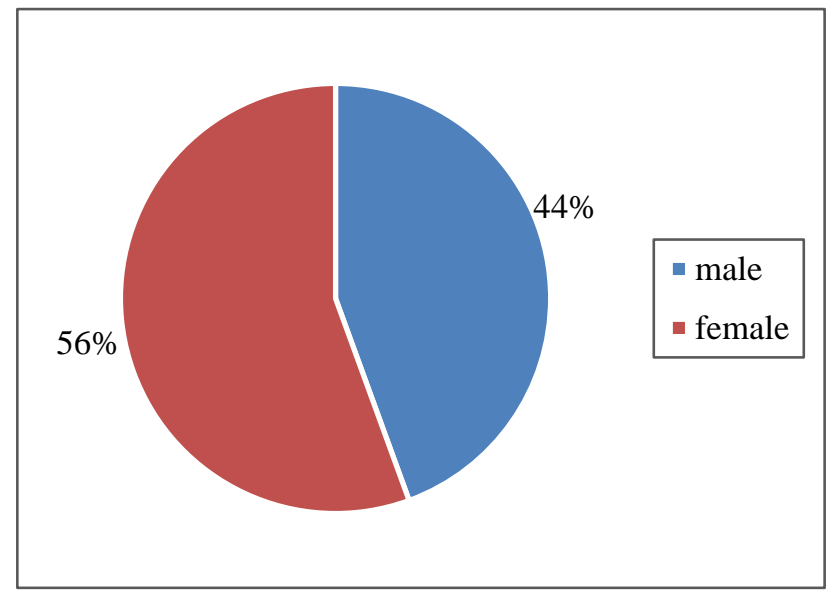

Figure 2: Percentage of subjects in the study according to sex.

\section{Mode of injury}

The major cause of fracture in present study was fall by either twisting, slipping or stumbling in 32 cases $(71 \%)$ and in 13 cases (29\%), fracture was due to road traffic accident.
Analysis of mode of injury and complications was done and chi-square value was 9.844 and $p$ value 0.363 which was found to be statistically insignificant (Figure 3).

Analysis of mode of injury and pain was done and chisquare value was 0.495 and $\mathrm{p}$ value 0.781 which was statistically insignificant.

Statistical analysis of mode of injury and result was done and chi-square was 0.184 and $\mathrm{p}$ value 0.980 which was insignificant.

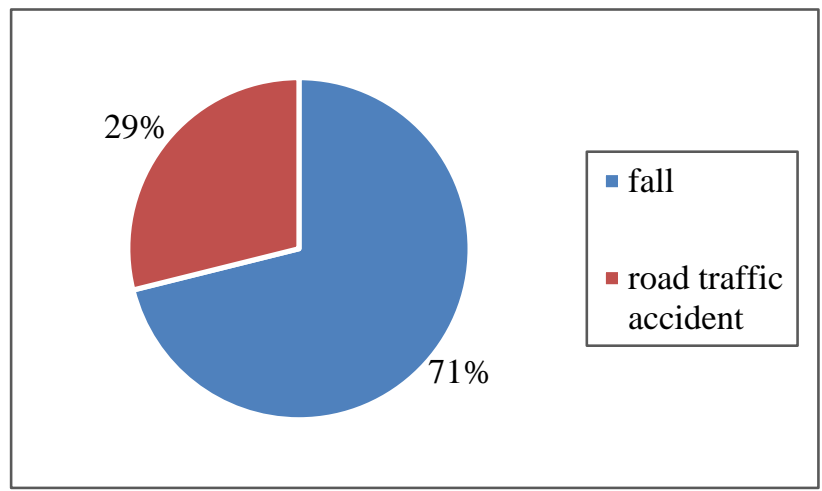

Figure 3: Percentage of subjects in the study according to mode of injury.

\section{Side of injury}

Right ankle was involved in $26(58 \%)$ patients and in 19 (42\%) patients left ankle was involved (Figure 4).

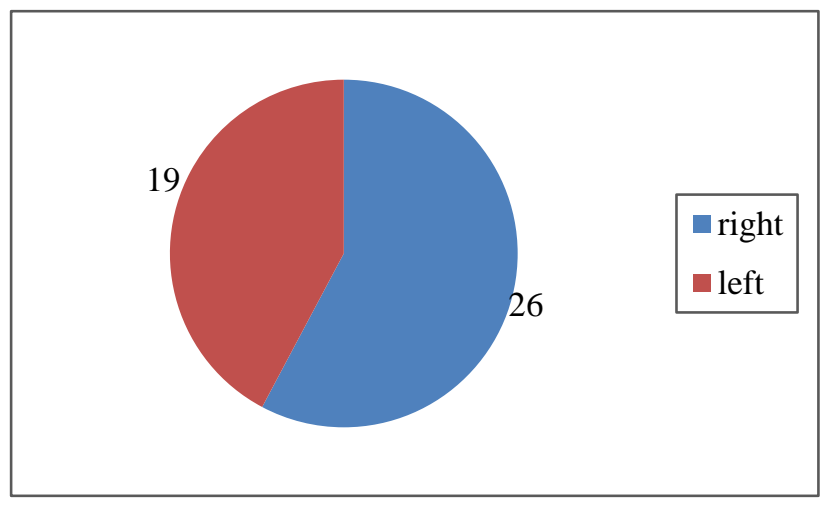

Figure 4: Percentage of subjects in the study according to side of injury.

\section{Type of injury}

In this study $21(47 \%)$ patients had supination external rotation injuries, which is the majority followed by 11 (24\%) patients having pronation abduction injury and 8 (18\%) patients pronation external rotation injury. Remaining $5(11 \%)$ patients had pronation abduction injury (Figure 5). 
Analysis of type of injury and complications was done and chi-square value was 23.444 and $p$ value was 0.661 which was statistically insignificant.

Analysis of type of injury and pain was done and chisquare value was 2.414 and $p$ value was 0.878 which was statistically insignificant.

Analysis of type of injury and result was done and chisquare value was 5.187 and p value was 0.818 which was found to be statistically insignificant.

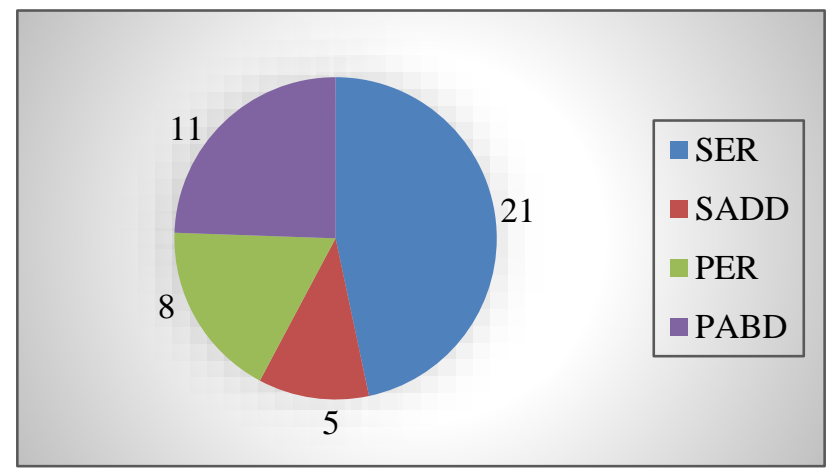

Figure 5: Percentage of subjects in the study according to type of injury.

\section{Comorbidities}

In this study 6 patients were having hypertension, 12 were having type II diabetes mellitus, 1 each had bronchial asthma and coronary artery disease. During the course of fracture treatment all the diabetic patients were brought under strict diabetic control. 8 out of 20 males were smokers and none of the females were having any addictions (Figure 6).

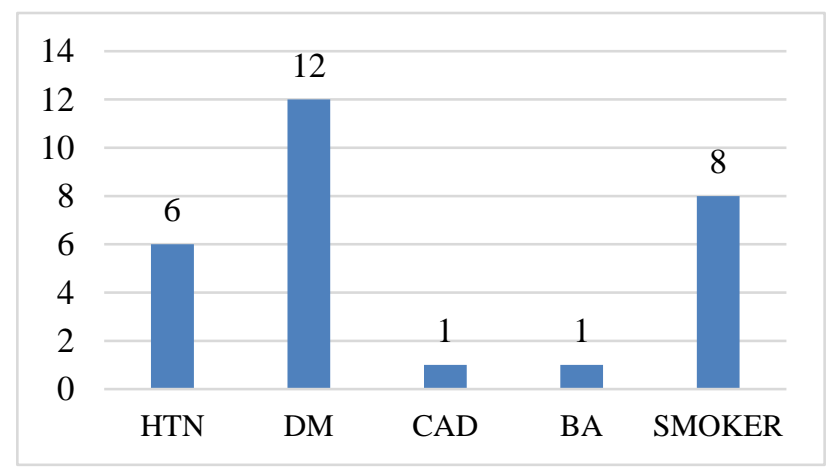

Figure 6: Percentage of co-morbidites.

Analysis of co-morbidities and result was done and chisquare value was 29.789 and $p$ value was 0.192 which was statistically insignificant.

Analysis of co-morbidities and pain was done and chisquare value was 9.396 and $\mathrm{p}$ value 0.896 which was statistically insignificant.
Analysis of DM and complications was done and chisquare value was 8.068 and $p$ value was 0.527 which was statistically insignificant.

Analysis of DM and pain was done and chi-square value was 4.675 and $p$ value was 0.097 which was statistically insignificant.

Analysis of DM and result was done and chi-square value was 7.361 and $p$ value was 0.061 which was statistically insignificant.

\section{Implants used}

Medial malleolus were used in $4 \mathrm{~mm}$ cannulated cancellous screw 34 cases, malleolar screw 9 cases, tension band wiring 1 case, $1 / 3$ rdtubular plate 1 case.

Lateral malleolus were used in $1 / 3$ rd tubular plate 39 cases.

Recon plate was used in 6 cases.

Syndesmotic screw (3.5mm cortical screw) was used in 7 cases (Figure 7).

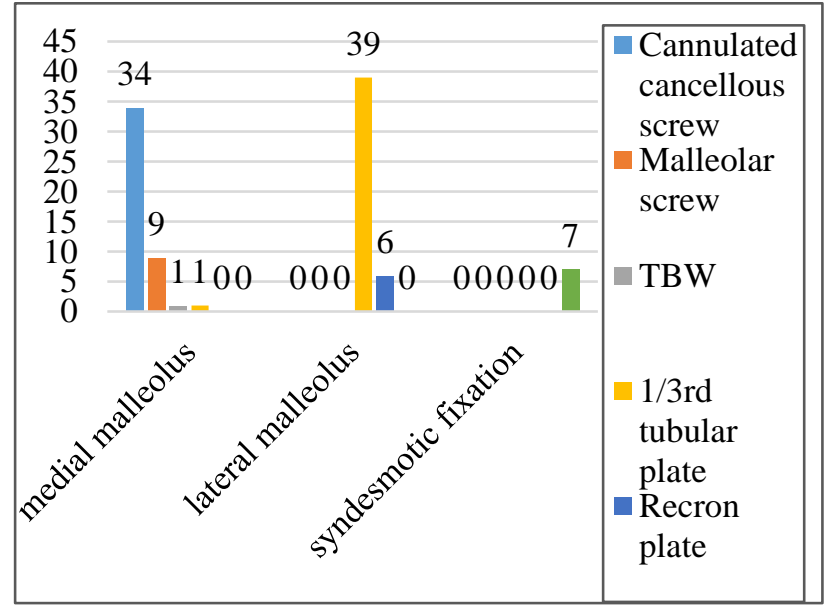

Figure 7: Implants used in present study.

\section{Complications}

3 patients had superficial skin infection which healed by 3 weeks. 2 patients had to undergo implant removal before 3 months due to unresolved infection at surgical site.

Statistical analysis of complications was done and chisquare value was 8.663 and $p$ value was 0.469 which was insignificant. Statistical analysis of comorbidities and complications was done and chi-square value was 35.596 and $\mathrm{p}$ value was 1.000 which was insignificant. 


\section{Final outcome}

Ankle pain

In this series 35 patients (78\%) had mild to moderate pain during strenuous activities and 10 patients $(22 \%)$ had pain with activities of daily living.

\section{Stability of ankle}

None of the patients had instability of ankle.

\section{Ability to walk}

$40(89 \%)$ of patients could walk desired distances with or without limp or mild pain. 5 patients $(11 \%)$ had moderate restriction in ability to walk.

\section{Ability to run}

$18(40 \%)$ patients were able to run desired distances without pain, 19 (42\%) patients were able to run desired distances with slight pain and $8(18 \%)$ patients had moderate restriction or ability to run short distance only.

\section{Ability to work}

$29(64 \%)$ patients were able to perform usual occupation without restriction and the rest $16(34 \%)$ patients were able to perform usual occupation with restriction in some strenuous activities.

\section{Motion of ankle}

$40(89 \%)$ patients had range of motion of the ankle within $10^{\circ}$ of uninjured ankle and $4(9 \%)$ patients were having motion within $20^{\circ}$ of uninjured ankle. The remaining 1 (2\%) patient had dorsiflexion of ankle less than 50.

\section{Radiological result}

40 patients $(89 \%)$ had intact ankle mortise with normal clear space, normal superior joint space and no talar tilt. 4 patients $(9 \%)$ had mild reactive changes at joint margin and remaining 1 patient $(2 \%)$ had severe narrowing of joint space $(<1 \mathrm{~mm})$, widening of medial clear space, sclerotic subchondral bone and osteophyte formation (Table 1).

\section{Composite score}

Excellent results were achieved in $13(29 \%)$, good in 16 $(36 \%)$, fair in $12(27 \%)$ and poor in $4(8 \%)$ of patients (Table 2).

Table 1: Final score according to subjective, objective and radiological criteria.

\begin{tabular}{|c|c|c|c|c|c|c|}
\hline Criteria & Grade a & Grade b & Grade c & Grade d & Grade e & Total \\
\hline Pain & 10 & 35 & 0 & 0 & 0 & 45 \\
\hline Stability of ankle & 45 & 0 & 0 & 0 & 0 & 45 \\
\hline Ability to walk & 25 & 15 & 5 & 0 & 0 & 45 \\
\hline Ability to run & 18 & 19 & 5 & 3 & 0 & 45 \\
\hline Ability to work & 29 & 16 & 0 & 0 & 0 & 45 \\
\hline Ankle movements & 40 & 4 & 0 & 0 & 1 & 45 \\
\hline Radiography & 40 & 4 & 0 & 0 & 1 & 45 \\
\hline
\end{tabular}

Table 2: Composite score.

\begin{tabular}{|lll|}
\hline Composite scores & Number of patients & Percentage $(\%)$ \\
\hline $\mathbf{9 6 - 1 0 0}$ (excellent) & 13 & 29 \\
\hline $\mathbf{9 1 - 9 5}$ (good) & 16 & 36 \\
\hline $\mathbf{8 1 - 9 0}$ (fair) & 12 & 27 \\
\hline $\mathbf{0 - 8 0}$ (poor) & 4 & 8 \\
\hline Total & 45 & 100 \\
\hline
\end{tabular}



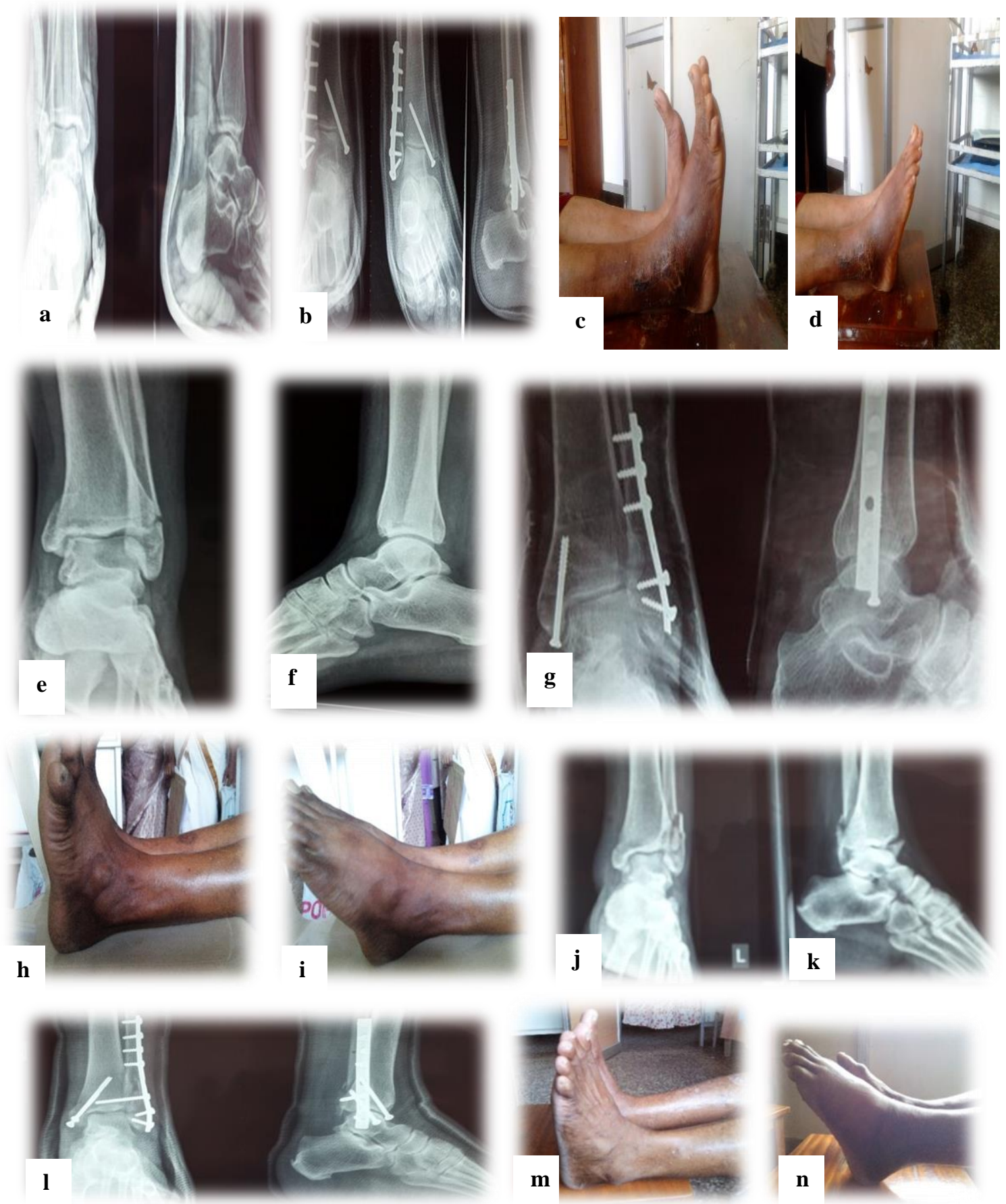

Figure 8: Clinical and radiological pictures of cases supination external rotation injury; (a) pre-operative X-ray, (b) post-operative X-ray (ORIF with $4 \mathrm{~mm} \mathrm{CCS}$ and 1/3rd tubular plate); (c, d) follow up at 6 months (dorsiflexion of ankle and plantar flexion of ankle), pronation external rotation injury; (e, f) pre-operative X-ray;

(g) post-operative X-ray (ORIF with $4 \mathrm{~mm}$ CCS and 1/3rd tubular plate); (h and i) follow up at 6 months (dorsiflexion of ankle and plantar flexion of ankle), pronation abduction injury; (j, k) pre-operative X-ray; (l) postoperative X-ray (ORIF with $4 \mathrm{~mm}$ CCS, 1/3rd tubular plate and syndesmotic screw); (m, n) follow up at 6 months (dorsiflexion of ankle and plantar flexion of ankle).

\section{DISCUSSION}

Evidence of healed ankle fractures has been described in the remains of mummies from ancient Egypt. A detailed account of lesions around ankle joint was given by Hippocrates as early as $300 \mathrm{BC}$. He mentioned that the ankle joint may subluxate and may be associated with fracture of both malleoli which would be either simple or compound. It was assumed that the compound fracture dislocation of ankle does not need any treatment because the patients probably die in 7 days. Sir Percival Pott (17141788) was a surgeon at St. Bartholomew's hospital, 
London in the year 1756. He sustained compound fracture of ankle due to fall while riding a horse. The treatment during this period was amputation for compound fracture having suffered he made a detailed description and studied the pathological anatomy of ankle fractures. He introduced the reposition in semi flexion to reduce the fracture. ${ }^{4}$

In 1771, Jean Pierre David was the first to try to explain the mechanism of injury in fractures of ankle and wrote that ligaments that held the fibula in combination with outward movement of the foot (external rotation) resulted in a fracture of the distal fibula. During the next 150 years, most experimental studies on the production of ankle injuries were done by French. In 1816, Dupuytren used a cadaver experiments to produce ankle fractures by abduction or outward movement of foot. ${ }^{5}$ In 1822, Sir Astley Cooper of London, described a wide range of ankle fractures including the anterior and posterior margins of lower end of tibia.

In 1828, Earl was the first to describe the posterior lip fracture of tibia. ${ }^{6}$

In 1840, Maisonneuve, a pupil of Dupuytren was the first and almost only surgeon before 20th century to emphasize the role of external rotation in the production of ankle fractures showing how the external rotation of the talus in the ankle mortise could produce the high fracture of fibula that bears his name. ${ }^{7}$ In 1848 , Tillaux described an external rotation fracture in which the anterolateral corner of the lower tibia was avulsed by the tibio-fibular ligament. ${ }^{8}$ In 1875, Wagstaffe described a fibular counterpart of the tillaux fracture. In 1894, Lane was the first to recommend operative treatment in order to achieve an anatomic reduction of ankle.

In 1911, Destot described the comminuted fracture of the tibial plafond that has since been referred to as pilon or pestle fracture. ${ }^{9}$ Destot used roentgenographic imagines to enhance his observations of ankle fractures. In 1922, Ashurst and Bromer, published a classic study on classification and mechanism of fractures of leg bones involving ankles. ${ }^{10}$ They divided the fractures into categories of adduction, abduction, external rotation and compression. Ashurst and Bromer were the first USG anatomic, surgical and radiographic studies to postulate their classification scheme, but they emphasized the bony components while ignoring the concomitant ligamentous injuries.

Almost 50 years after Earl's report on posterior lip fractures, Nelaton described fracture of the anterior lip of tibia. ${ }^{11}$ Muller (1945) recommended open reduction and internal fixation of the ankle fractures and allowed immediate movement of the involved joint and the adjacent muscles. Bosworth in 1947, provided the first description of a low, external rotation fracture of the fibula in which the displace proximal fragment became locked behind the posterior tibia, where it was held by an intact interosseous membrane. ${ }^{12}$
The first and perhaps the most important contribution to the understanding of ankle fractures is credited to LaugeHansen in 1942. His doctoral thesis was not widely read or appreciated until his first english publication in 1948. This was followed by other important articles further defining and explaining the basis of sequential ankle fracture injury based on experimental and radiographic studies. Two additional periods developed since Lauge-Hansen classification. The AO-ASIF period (1957) of ankle fracture case was pioneered by Willenegger Allgrower, Muller and Schneider. Collectively this group pursued on bold new course of operative treatment based on unique metallic implants and bio-mechanical principles. Weber devised a classification scheme based on the original principles of Danis (1947-1949) which became known as the Danis-Weber classification of AO (1972-1975).

In 1994, Wilson et al described the malleolar fractures resulting from isolated plantar flexion injuries both malleoli are fractured obliquely in the sagittal plank, though the lateral malleolar fracture runs posteriorly and upwards, whereas medial malleolar fracture courses posteriorly and downward. The results of 144 malleolar fractures during a 10 year period that were classified and treated according to the AO system. Assessment of outcome was done using the scoring system of Baird and Jackson. Excellent and good results were achieved in 107 of the 144 patients surgically treated. ${ }^{17}$

Majority of bimalleolar fractures that we studied were supination external rotation injuries. The most common aetiology being road traffic accident. Females are more prone with age incidence of 61-70 years. Understanding the mechanism of injury is essential for good reduction and internal fixation. The bend of lateral malleolus should be reproduced during lateral plating for fibula. Fibular length should be maintained for good ankle stability. Good anatomical reduction is essential for good clinical outcome irrespective of the type of fracture. The results of operative fixation are satisfactory in $90 \%$ of patients. Chances of non-union of medial malleolus due to periosteal interposition is avoided. Most of the complications were minor and resolved within three weeks. Tension band wiring is the method preferred for small fragments and osteoporotic bone. Cast immobilization for four weeks did not affect movements at ankle because the duration was very short.

\section{CONCLUSION}

Majority of bimalleolar fractures that we studied were supination external rotation injuries. The most common aetiology being road traffic accident. Females are more prone with age incidence of 61-70 years. Understanding the mechanism of injury is essential for good reduction and internal fixation. The bend of lateral malleolus should be reproduced during lateral plating for fibula. Fibular length should be maintained for good ankle stability. Good anatomical reduction is essential for good clinical outcome irrespective of the type of fracture. The results of operative 
fixation are satisfactory in $90 \%$ of patients. Chances of non-union of medial malleolus due to periosteal interposition is avoided. Most of the complications were minor and resolved within three weeks. Tension band wiring is the method preferred for small fragments and osteoporotic bone. Cast immobilization for four weeks did not affect movements at ankle because the duration was very short.

\section{ACKNOWLEDGEMENTS}

We would like to thank all our patients who sincerely formed very important part of this study.

Funding: No funding sources

Conflict of interest: None declared

Ethical approval: The study was approved by the institutional ethics committee

\section{REFERENCES}

1. Court-Brown CM, Caesar B. Epidemiology of adult fractures: a review. Injury. 2006;37(8):691-7.

2. Weert EMVSD, Lieshout EMMV, Vries MRD, Elst MVD, Schepers T. Determinants of outcome in operatively and non-operatively treated Weber-B ankle fractures. Arch Orthop Trauma Surg. 2012;132(2):257-63.

3. Michelson JD. Fractures about the ankle. J Bone Joint Surg Am. 1995;77(1):142-52.

4. Pott P. Some Few general remarks on fractures and dislocations. New Antiquarian. 1768;8(4):126.

5. Dupuytren G. Fractures of the lower extremity of the fibula, and subluxations of the foot. Med Classic. 1939;4:151-72.

6. Earl H. Simple succeeded by compound dislocation of the inferior extremity of the tibia with fracture of its posterior edge comminuted fracture of the fibula. Lancet. 2:346-8

7. Maisonneuve MGT. Resurchessur la fracture du perone. Arch Gen Med. 1940;7:165-87.
8. Tillaux D. Recherches clinique setexperimentalessur les fractures malleolaires. Bull Acad Med. 1872;1:817.

9. Michelson J, Moskovitz P, Labropoulos P. The nomenclature for intra-articular vertical impact fractures of the tibial plafond: pilon versus pylon. Foot Ankle Int. 2004;25(3):149-50.

10. Ashurst APC, Bromer RS. Classification and mechanism of fractures of the legbones involving the ankle: based on a study of three hundred cases from the episcopal hospital. Arch Surg. 1922;4:51-129.

11. Nelaton A. Elements of pathologic chirorgicale. 2nd ed. Paris: Germer-Baillaine; 1874: 296.

12. Bosworth DM. Fracture-dislocation of the ankle with fixed displacement of the fibula behind the tibia. J Bone Joint Surg Am. 1947;29:130-5.

13. Lauge-Hansen N. Fractures of the ankle. III: genetic roentgenologic diagnosis of fractures of the ankle. Am J Roentgenol Radium Ther Nucl Med. 1954;71(3):456-71.

14. Hahn DM, Colton CL. Malleolar fractures. AO Principles of fracture management. New York: Thieme; 2001: 583-4.

15. Wilson FC, Phillips HO Gilbert JA. Plantar flexion injuries of the ankle. An experimental study. Clin Orthop Relat Res. 1994;306:97-102.

16. Gougoulias N, Khanna A, Sakellariou A, Maffulli N, et al. Supination-external rotation ankle fractures: stability a key issue. Clin Orthop Relat Res. 2010;468(1):243-51.

17. Tejwani NC, McLaurin TM, Walsh M, Bhadsavle S, Koval KJ, Egolet KA. Are outcomes of bimalleolar fractures poorer than those of lateral malleolar fractures with medial ligamentous injury. J Bone Joint Surg. 2007;89(7):1438-41.

Cite this article as: Gangadhran N, Pillai MG. Study on functional outcome of bimalleolar ankle fractures treated by open reduction and internal fixation. Int J Res Orthop 2021;7:518-25. 